TITLE:

\title{
Theoretical trend of ion exchange ability with divalent cations in hydroxyapatite
}

$\operatorname{AUTHOR}(S):$

Matsunaga, Katsuyuki; Inamori, Hiroki; Murata, Hidenobu

\section{CITATION:}

Matsunaga, Katsuyuki ... [et al]. Theoretical trend of ion exchange ability with divalent cations in hydroxyapatite. PHYSICAL REVIEW B 2008, 78(9): 094101.

ISSUE DATE:

2008-09

URL:

http://hdl.handle.net/2433/84632

RIGHT:

(c) 2008 The American Physical Society 
PHYSICAL REVIEW B 78, 094101 (2008)

\title{
Theoretical trend of ion exchange ability with divalent cations in hydroxyapatite
}

\author{
Katsuyuki Matsunaga, ${ }^{1,2}$ Hiroki Inamori, ${ }^{1}$ and Hidenobu Murata ${ }^{1}$ \\ ${ }^{1}$ Department of Materials Science and Engineering, Kyoto University, Yoshida-Honmachi, Sakyo, Kyoto 606-8501, Japan \\ ${ }^{2}$ Nanostructures Research Laboratory, Japan Fine Ceramics Center, 2-4-1, Mutsuno, Atsuta, Nagoya 456-8587, Japan
}

(Received 18 May 2008; published 3 September 2008)

\begin{abstract}
First-principles calculations are performed for hydroxyapatite (Hap) in order to investigate the relative ion exchange ability with divalent cations such as $\mathrm{Mg}^{2+}, \mathrm{Ni}^{2+}, \mathrm{Cu}^{2+}, \mathrm{Zn}^{2+}, \mathrm{Sr}^{2+}, \mathrm{Cd}^{2+}, \mathrm{Ba}^{2+}$, and $\mathrm{Pb}^{2+}$. $\mathrm{Their}^{2}$ ionic substitutional energies are calculated from total energies of supercells and chemical potentials for $\mathrm{Ca}^{2+}$ and the foreign cations determined under chemical equilibrium between HAp and its saturated solution. It is found that, in most cases, the ion exchange ability is basically dependent on the ionic sizes and the larger or smaller-sized cations than $\mathrm{Ca}^{2+}$ tend to exhibit more difficulty of substitution for $\mathrm{Ca}^{2+}$ in $\mathrm{HAp}$. However, $\mathrm{Pb}^{2+}$ exhibits the extremely small substitutional energy, which originates from covalent bonds with the adjacent oxygen atoms. In particular, $\mathrm{Pb}^{2+}$ at the $\mathrm{Ca}-1$ site of $\mathrm{HAp}$ has covalency with the second-nearest-neighboring oxygen atoms as well as the first nearest-neighboring ones. The covalent bond formation plays an important role for the distinct ion exchange ability for $\mathrm{Pb}^{2+}$ by HAp observed experimentally.
\end{abstract}

DOI: 10.1103/PhysRevB.78.094101

PACS number(s): 61.72.J-, 71.15.Mb

\section{INTRODUCTION}

Hydroxyapatite (HAp) $\left[\mathrm{Ca}_{10}\left(\mathrm{PO}_{4}\right)_{6}(\mathrm{OH})_{2}\right]$ is now attracting much attention in materials science due to its practical application to biomaterials. In addition, since HAp has versatile physical and chemical properties, it is expected to be utilized as catalysts, chromatographic adsorbents for protein separation, scaffold materials in tissue engineering, and so on. One of the interesting properties of HAp is an ion exchange ability for various foreign cations and anions and would be useful to remove harmful ions in waste water. ${ }^{1,2}$ It is known that HAp minerals in human bones also contain a variety of foreign ions. ${ }^{3}$ The incorporated impurities and dopants in HAp are successively released into or uptake from the surrounding body fluids during the bone remodeling processes. It can be said, therefore, that the ion exchange of HAp is also a key factor to determine the biological properties of HAp.

There were a number of experimental reports on ion exchange properties of synthetic HAp materials. ${ }^{1-7}$ Suzuki et $a l .{ }^{1}$ reported the ranking of ion exchange ability of $\mathrm{Cd}^{2+}, \mathrm{Zn}^{2+}>\mathrm{Ni}^{2+}>\mathrm{Ba}^{2+}, \mathrm{Mg}^{2+}$ and showed the ranking of $\mathrm{Pb}^{2+}>\mathrm{Cu}^{2+}>\mathrm{Mn}^{2+} \cong \mathrm{Co}^{2+}$ in their separate paper. ${ }^{2}$ Takeuchi and $\mathrm{Arai}^{4}$ also investigated the removal of $\mathrm{Pb}^{2+}, \mathrm{Cu}^{2+}$, and $\mathrm{Cd}^{2+}$ by synthetic $\mathrm{HAp}$ and found that $\mathrm{Pb}^{2+}$ ions are more readily incorporated into HAp by exchange with $\mathrm{Ca}^{2+}$, as compared to $\mathrm{Cu}^{2+}$, and $\mathrm{Cd}^{2+}$. As a general trend, it seems that cations having the larger atomic numbers tend to be more easily exchanged with $\mathrm{Ca}^{2+}$ in HAp.

The difference in ion exchange ability of divalent cations was previously interpreted by ionic sizes and electronegativity of the exchanged cations. From simple geometrical considerations, it is easily expected that cations having similar ionic radii with $\mathrm{Ca}^{2+}\left(0.10 \mathrm{~nm}\right.$ in the sixfold coordination $\left.{ }^{8}\right)$ can be favorably exchanged with $\mathrm{Ca}^{2+}$ in HAp. Suzuki et al. ${ }^{2}$ argued that cations easily uptake from an aqueous solution into HAp tend to have ionic radii of around $0.09-0.13 \mathrm{~nm}$.
Moreover, they also mentioned the tendency of the good ion exchange ability for cations having much higher electronegativity than $\mathrm{Ca}^{2+}$, which may suggest the importance of the detailed chemical bonding states around the exchanged cations. Recently, Zhu et al. ${ }^{9}$ studied the atomic structures of HAp solid solutions with $\mathrm{Pb}^{2+}, \mathrm{Sr}^{2+}$, and $\mathrm{Cd}^{2+}$ and argued the site preference in the HAp lattice based on the ionic sizes and electronegativity. Although the ionic sizes and electronegativity are convenient measures to qualitatively interpret the difference in ion exchange ability, however, it is desirable to reveal a physical and chemical origin of the ion exchange ability in more detail. In this regard, first-principles calculations have been proven to be suitable for studying electronic structures and energetics of substitutional defects in materials.

In this study, various kinds of substitutional divalent cations in HAp are calculated in a first-principles manner, and the defect formation energies by ion exchange with $\mathrm{Ca}^{2+}$ in HAp are evaluated from total energies of supercells and chemical potentials determined under solid-liquid equilibrium. It is noted that this type of calculations corresponds to bulk substitutions of foreign cations in HAp. Since actual ion exchange takes place through interfaces between HAp and aqueous solution, structural characteristics of HAp surfaces in contact with solution may affect absorption and incorporation of foreign cations into HAp. ${ }^{10}$ Nevertheless, it is beneficial, as a first step, to reveal essential acceptability of foreign cations by bulk HAp via ion exchange from calculations of the bulk substitutions.

A number of first-principles studies on substitutional defects in HAp have been reported so far. ${ }^{11-17}$ However, most of the previous studies investigated atomic and electronic structures around substitutional defects and did not systematically reveal the trend in stability of foreign cations substituting for $\mathrm{Ca}^{2+}$ in HAp by ion exchange. The results obtained by thermodynamic treatments of first-principles total energies are compared with available experimental data, and the 
origin of the ion exchange ability of HAp will be discussed in terms of atomic and electronic structures localized around the exchanged divalent cations.

\section{COMPUTATIONAL METHODS}

The projector-augmented-wave (PAW) method is used for electronic structure calculations of substitutional defects in HAp using the VASP code. ${ }^{18-20}$ In the cases of substitutional transition-metal ions having unfilled $d$ orbitals $\left(\mathrm{Ni}^{2+}\right.$ and $\mathrm{Cu}^{2+}$ ), spin polarization is also taken into account. The generalized gradient approximation (GGA) for the exchangecorrelation potential is employed. ${ }^{21}$ Electronic wave functions are expanded by plane waves up to a cutoff energy of $500 \mathrm{eV}$. Brillouin-zone integration is performed on $k$-point meshes by the Monkhorst-Pack scheme. ${ }^{22}$ All atoms in supercells for defect calculations are relaxed, and the structural optimization is truncated when their forces converge to less than $0.05 \mathrm{eV} / \AA$.

The present study deals with eight kinds of substitutional divalent cations in HAp such as $\mathrm{Mg}^{2+}, \mathrm{Ni}^{2+}, \mathrm{Cu}^{2+}, \mathrm{Zn}^{2+}$, $\mathrm{Sr}^{2+}, \mathrm{Cd}^{2+}, \mathrm{Ba}^{2+}$, and $\mathrm{Pb}^{2+}$. This is mainly because the ion exchange behavior for these ions by HAp was experimentally examined ${ }^{1-7}$ and also the inclusion of many of these ions in HAp are known to play an important biological role. It is noted that the substitutional cases of $\mathrm{Mg}^{2+}$ and $\mathrm{Zn}^{2+}$ ions in HAp were already reported in our previous paper ${ }^{17}$ and the results are also partly used here for comparison. For the defect calculations, 352-atom supercells generated from the hexagonal crystal structure of HAp are used, ${ }^{3,23}$ and one of the $\mathrm{Ca}$ ions in the perfect supercell is replaced by a particular foreign cation to generate the defective supercell. More details of the supercell construction were described elsewhere. ${ }^{17,24}$ In the supercell calculations, only the $\Gamma$ point is used for the Brillouin-zone sampling.

Two inequivalent $\mathrm{Ca}$ sites, $\mathrm{Ca}-1$ and $\mathrm{Ca}-2$, in $\mathrm{HAp}$ are replaced by the substitutional cations. Local atomic configurations of $\mathrm{Ca}-1$ and $\mathrm{Ca}-2$ are illustrated in Fig. 1. The Ca-1 site is surrounded by six $\mathrm{PO}_{4}^{3-}$ tehrahedra, where six oxygen ions at the vertices of $\mathrm{PO}_{4}^{3-}$ are located at the first nearestneighboring $(\mathrm{NN})$ sites and additional three oxygen ions are present at the second $\mathrm{NN}$ sites. The $\mathrm{Ca}-2$ site is also coordinated by six oxygen atoms at the first NN sites, and yet one of the first $\mathrm{NN}$ oxygen atoms belongs to the $\mathrm{OH}$ group. In addition, one oxygen atom is located at the second $\mathrm{NN}$ site. It is noted, therefore, that the atomic coordination difference between the two Ca sites is sometimes described by the oxygen coordination numbers within the second NN atomic coordination shell, the ninefold coordination for $\mathrm{Ca}-1$ and the sevenfold for Ca-2.

From total energies $E_{\mathrm{T}}$ of the HAp supercells with or without the substitutional defects, the defect formation energies $\left(\Delta H_{\mathrm{f}}\right)$ are evaluated. When a substitutional ionic species $\mathrm{M}^{2+}$ is exchanged by a $\mathrm{Ca}^{2+}$ in $\mathrm{HAp}, \Delta H_{\mathrm{f}}$ can be given by

$$
\Delta H_{\mathrm{f}}=E_{\mathrm{T}}(\text { defective })-E_{\mathrm{T}}(\text { perfect })+\mu_{\mathrm{Ca}^{2+}}-\mu_{\mathrm{M}^{2+}} .
$$

It is noted here that the substitutional cations are isovalent with $\mathrm{Ca}^{2+}$, and thus additional charge compensating defects do not need to be considered for the ion exchange. (a)

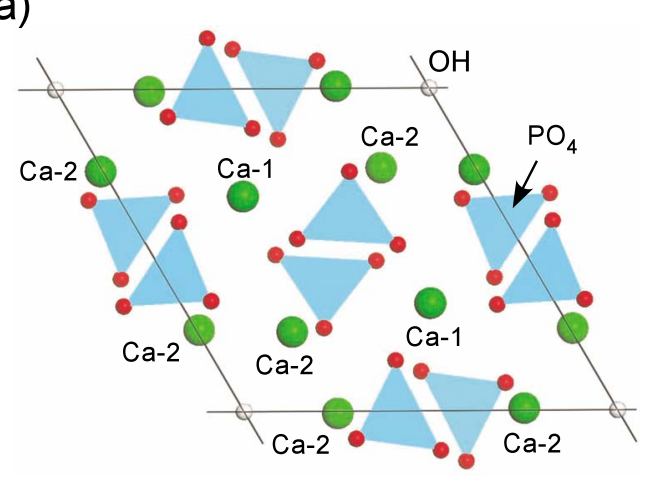

(b)

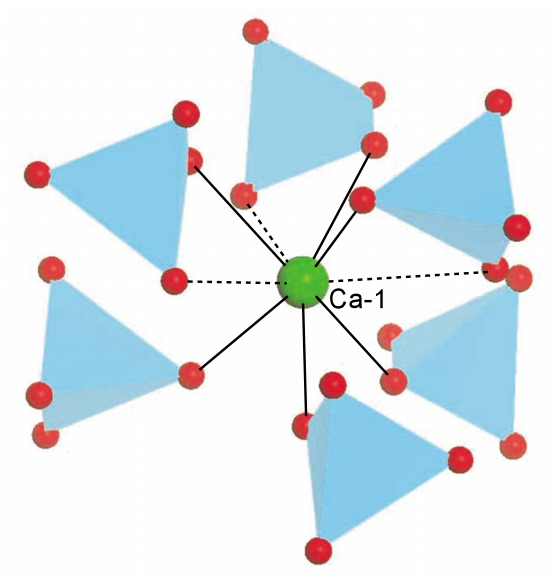

(c)

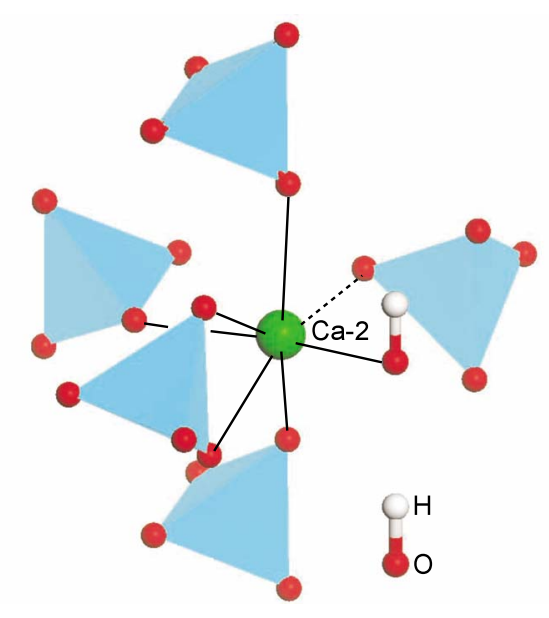

FIG. 1. (Color online) (a) Crystal structure of HAp viewed along the $c$ axis, (b) local atomic structures of $\mathrm{Ca}-1$, and (c) $\mathrm{Ca}-2$. In the illustrations of (b) and (c), the first NN oxygen ions are indicated by connecting with the $\mathrm{Ca}$ ions with the solid lines, while the second NN oxygen ions with the broken lines.

$\mu_{\mathrm{Ca}^{2+}}$ and $\mu_{\mathrm{M}^{2+}}$ in Eq. (1) indicate chemical potentials of $\mathrm{Ca}^{2+}$ and $\mathrm{M}^{2+}$, which are determined from a particular chemical equilibrium. In this study, it is assumed that HAp crystals equilibrate with an aqueous solution saturated with respect to HAp and containing a particular amount of $\mathrm{M}^{2+}$ ions. According to the thermodynamic treatment for ions in solution, ${ }^{25,26}$ the chemical-potential difference in Eq. (1) can be expressed as 


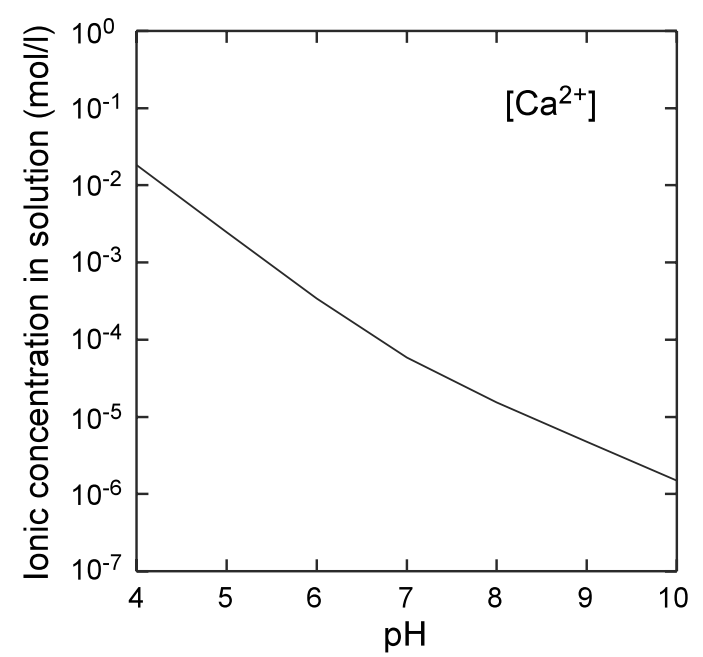

FIG. 2. Equilibrium $\mathrm{Ca}^{2+}$ concentration in the saturated aqueous solution as a function of solution $\mathrm{pH}$.

$$
\mu_{\mathrm{Ca}^{2+}}-\mu_{\mathrm{M}^{2+}}=\mu_{\mathrm{Ca}^{2+},{ }_{\mathrm{aq}}}^{\circ}-\mu_{\mathrm{M}^{2+}, \mathrm{aq}}^{\circ}+k_{\mathrm{B}} T \ln \left(a_{\mathrm{Ca}^{2+}} / a_{\mathrm{M}^{2+}}\right),
$$

where $\mu_{\mathrm{M}^{2+} \text {,aq }}^{\circ}$ and $a_{\mathrm{M}^{2+}}$ are the standard chemical potential and the activity of a cation in solution, respectively. $k_{\mathrm{B}}$ is the Boltzmann constant and a temperature of $T$ is set at $298 \mathrm{~K}$ throughout the present study. The $\mu_{\mathrm{Ca}^{2+}, \mathrm{aq}}^{\circ}-\mu_{\mathrm{M}^{2+}, \mathrm{aq}}^{\circ}$ term is further written using the standard Gibbs formation energies for ions in aqueous solution $\Delta G_{\mathrm{f}}^{\circ}\left(\mathrm{M}^{2+}\right.$, aq $)$ as $^{17}$

$$
\begin{aligned}
\mu_{\mathrm{Ca}^{2+}, \mathrm{aq}}^{\circ}-\mu_{\mathrm{M}^{2+}, \mathrm{aq}}^{\circ}= & \Delta G_{\mathrm{f}}^{\circ}\left(\mathrm{Ca}^{2+}, \mathrm{aq}\right)-\Delta G_{\mathrm{f}}^{\circ}\left(\mathrm{M}^{2+}, \mathrm{aq}\right) \\
& +\mu_{\mathrm{Ca}, \mathrm{s}}^{\circ}-\mu_{\mathrm{M}, \mathrm{s}}^{\circ} .
\end{aligned}
$$

The experimental $\Delta G_{\mathrm{f}}^{\circ}$ values are tabulated in the thermodynamic data, which are used in this study. ${ }^{27}$ On the other hand, $\mu_{\mathrm{Ca}, \mathrm{s}}^{\circ}$ and $\mu_{\mathrm{M}, \mathrm{s}}^{\circ}$ indicate chemical potentials of solid $\mathrm{Ca}$ and metal M. In this case, these quantities are considered to be the total energies per atom for the pure metals having stable crystal structures in the standard state, which are also calculated in a first-principles manner.

Regarding the ionic activity term of Eq. (2), the activity coefficients are assumed to be unity in this study. This is because HAp is sparing soluble and its saturated solution can be regarded as a dilute solution. The ionic concentrations of impurity ions $\left[\mathrm{M}^{2+}\right]$ are assumed to be a particular value, and then the calcium concentration in solution $\left[\mathrm{Ca}^{2+}\right]$ is determined from the solubility of product for HAp, the ionic product of water, three different acid dissociation constants for phosphate ions $\left(\mathrm{HPO}_{4}^{2-}=\mathrm{PO}_{4}^{3-}+\mathrm{H}^{+}, \mathrm{H}_{2} \mathrm{PO}_{4}^{-}=\mathrm{HPO}_{4}^{2-}+\mathrm{H}^{+}\right.$, and $\mathrm{H}_{3} \mathrm{PO}_{4}=\mathrm{H}_{2} \mathrm{PO}_{4}^{-}+\mathrm{H}^{+}$), and charge-neutrality requirement in solution. More details of the computational procedure to evaluate concentrations of ionic species in the saturated solution can be found elsewhere. ${ }^{17,24}$ In Fig. 2, only the calcium concentration in solution $\left[\mathrm{Ca}^{2+}\right]$ as a function of $\mathrm{pH}$ is depicted. Since $\left[\mathrm{Ca}^{2+}\right]$ depends on the solution $\mathrm{pH}$ value, ${ }^{17,24,28}$ the defect formation energies calculated from Eq. (1) also vary against the $\mathrm{pH}$ condition of the aqueous solution.

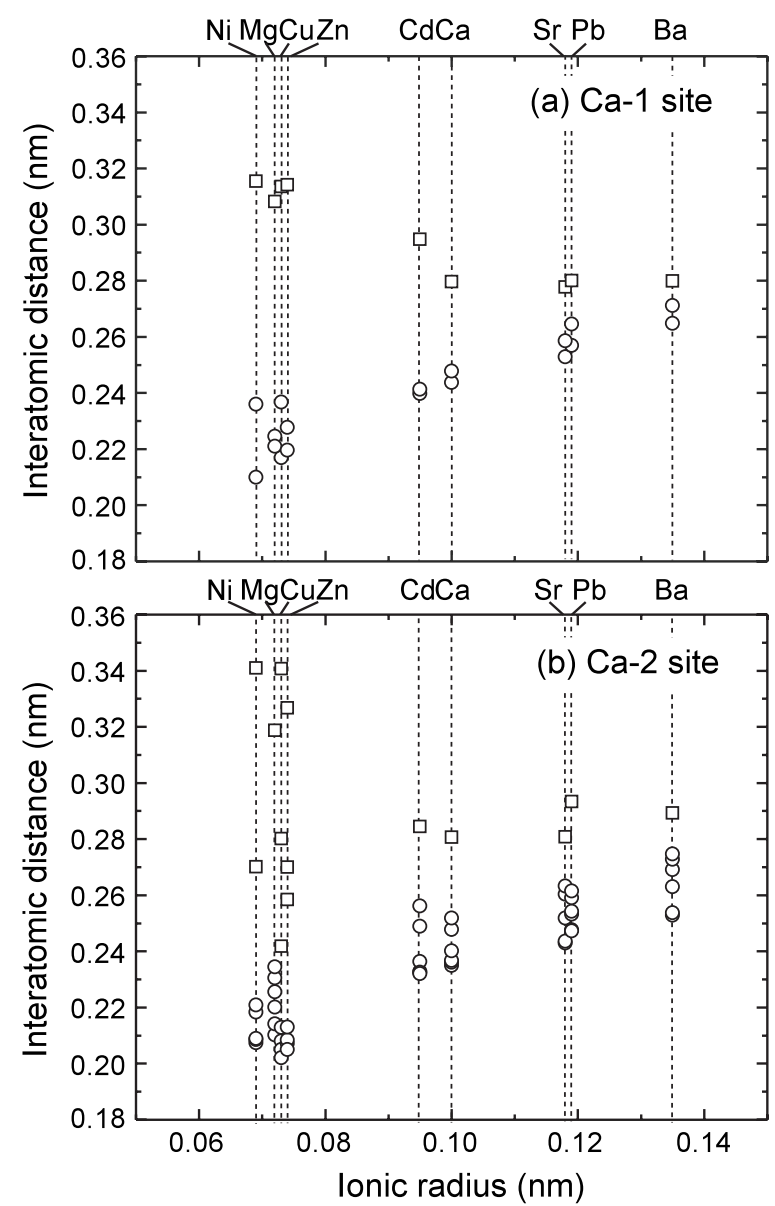

FIG. 3. Interatomic distances from the $\mathrm{Ca}$ ions to the neighboring oxygen ions against the ionic radii of the substituted cations. For the ionic radii, the experimental values in the sixfold coordination are used (Ref. 8). The distances to the first NN oxygen ions are plotted by open circles, while those to the second NN oxygen by open squares.

\section{RESULTS AND DISCUSSION}

\section{A. Structural characteristics around exchanged cations}

When foreign divalent ions $\mathrm{M}^{2+}$ are substituted for $\mathrm{Ca}^{2+}$ of HAp, the ionic sizes are generally different from that of $\mathrm{Ca}^{2+}$, and thus the surrounding ions may undergo atomic relaxation. In this section, therefore, characteristics of the atomic structures around the substitutional cations in HAp are investigated. Figure 3 displays the calculated interatomic distances between $\mathrm{M}^{2+}$ and its surrounding oxygen ions as a function of the ionic radii. In this case, the $\mathrm{Ca}-1$ and $\mathrm{Ca}-2$ sites in the perfect HAp lattice are basically sixfold coordinated by oxygen ions at the first NN sites, and thus the experimental ionic radii in the sixfold coordination by Shannon are used. ${ }^{8}$ In perfect HAp, the Ca- 1 ion is coordinated by three of the first NN oxygen ions with a bond length of 0.244 $\mathrm{nm}$, and the other three are located at $0.248 \mathrm{~nm}$ in distance from Ca-1. At the second NN sites, three oxygen ions are also present with a bond length of $0.280 \mathrm{~nm}$. On the other hand, the local atomic configuration of $\mathrm{Ca}-2$ is more complicated than that of $\mathrm{Ca}-1$. The $\mathrm{Ca}-2$ ion is also surrounded by six oxygen ions at the first NN sites, and yet their distances 
from Ca-2 vary from 0.236 to $0.252 \mathrm{~nm}$. An oxygen ion at the second NN site is situated at a distance of $0.281 \mathrm{~nm}$ from Ca-2.

When the divalent foreign ions replace $\mathrm{Ca}-1$, the interatomic distances from $\mathrm{Ca}-1$ strongly depend on their ionic sizes [see Fig. 3(a)]. For the smaller-sized cations of $\mathrm{Ni}^{2+}$, $\mathrm{Mg}^{2+}, \mathrm{Cu}^{2+}$, and $\mathrm{Zn}^{2+}$, the first $\mathrm{NN}$ oxygen ions tend to considerably move toward $\mathrm{Ca}-1$ (more than $7 \%$ relaxation on average), whereas the second $\mathrm{NN}$ oxygen ions undergo outward relaxation by more than $10 \%$ in distance. This can be explained from the local atomic configuration of $\mathrm{Ca}-1$, as shown in Fig. 1(b). The first and second $\mathrm{NN}$ oxygen ions are situated at the vertices of the adjacent $\mathrm{PO}_{4}^{3-}$ tetrahedra, and substitution of the smaller-sized cations brings about inward displacements of the $\mathrm{PO}_{4}^{3-}$ groups toward the Ca- 1 site. However, the inward relaxation of the surrounding $\mathrm{PO}_{4}^{3-}$ groups simultaneously accompanies close proximity of the oxygen ions, and then the $\mathrm{PO}_{4}^{3-}$ groups rotate so as to minimize electrostatic repulsions between the oxygen ions at their vertices. As a result, the second NN oxygen ions tend to move away from the Ca-1 site, as shown in Fig. 3(a). Such a behavior of the surrounding ions can be found also in the $\mathrm{Cd}^{2+}$ case, although the atomic relaxations around $\mathrm{Cd}^{2+}$ are much smaller due to its similar ionic radius with $\mathrm{Ca}^{2+}$.

In the cases of the larger-sized cations $\left(\mathrm{Sr}^{2+}, \mathrm{Pb}^{2+}, \mathrm{Ba}^{2+}\right)$ at the Ca-1 site, the first NN oxygen ions displace their positions away from the $\mathrm{Ca}-1$ site. For instance, the $\mathrm{Ba}-\mathrm{O}$ distances at the first NN sites are by about $9 \%$ larger than those of Ca-O. It is noted, however, that the distances of the second NN oxygen ions from the larger cations at the Ca- 1 site are almost the same with that from Ca-1 in perfect HAp.

Interatomic distances of the foreign cations at $\mathrm{Ca}-2$ vary in the similar way to the Ca-1 substitutional case, depending on the ionic radii [Fig. 3(b)]. As stated in Sec. II, however, the atomic configuration at $\mathrm{Ca}-2$ in the original HAp lattice exhibits lower symmetry than at $\mathrm{Ca}-1$, and thus the substituted cations exhibit somewhat wide variations in the interatomic distances with the first NN oxygen ions. As a result, some of the smaller-sized cations tend to have smaller coordination numbers to oxygen at the first NN sites, as compared to the case in perfect HAp (sixfold coordination). In the cases of $\mathrm{Cu}^{2+}$ and $\mathrm{Zn}^{2+}$, their coordination numbers to the first NN oxygen ions are four with bond lengths of $0.207-$ $0.213 \mathrm{~nm}$, and the other oxygen ions at the sites beyond the second NN coordination shell are located at a distance of more than $0.24 \mathrm{~nm}$. The decreased coordination numbers of $\mathrm{Cu}^{2+}$ and $\mathrm{Zn}^{2+}$ can be understood from the fact that these ions have the fourfold coordination with oxygen in bulk $\mathrm{CuO}$ and $\mathrm{ZnO}$. Likewise, the coordination number of $\mathrm{Ni}^{2+}$ to the first NN oxygen is found to be 5 , and their bond lengths range from 0.210 to $0.221 \mathrm{~nm}$. $\mathrm{Ni}^{2+}$ ions favor the sixfold coordination to oxygen in bulk $\mathrm{NiO}$, but the coordination number decreases from 6 to 5 in HAp, because of its extremely small ionic size and the resultant electrostatic repulsions between the surrounding oxygen ions.

\section{B. Energetics of ionic substitution}

Substitutional energies of different divalent cations $\mathbf{M}^{2+}$ by exchange with $\mathrm{Ca}^{2+}$ in HAp are evaluated. As a typical

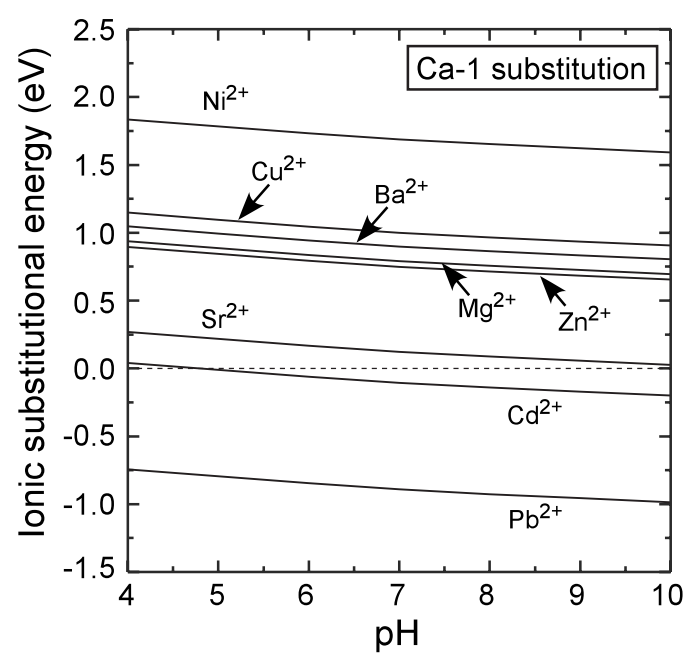

FIG. 4. Ionic substitutional energies at the Ca-1 site of HAp against the solution $\mathrm{pH}$.

example, the ionic substitutional energies at the $\mathrm{Ca}-1$ site are plotted against $\mathrm{pH}$ in Fig. 4. These results are obtained under assumption of the chemical equilibrium of HAp with the HAp-saturated aqueous solution having the impurity concentration $\left[\mathrm{M}^{2+}\right]$ of $1.0 \times 10^{-3} \mathrm{~mol} / 1$ at $298 \mathrm{~K}$. It is noted here that the substitutional energies also depend on $\left[\mathrm{M}^{2+}\right]$ in the solution. It is confirmed that the substitutional energies for all impurities systematically decrease by about $0.12 \mathrm{eV}$ in the case of the larger concentration $\left[\mathrm{M}^{2+}\right]=1.0 \times 10^{-1} \mathrm{~mol} / 1$ whereas increase by around $0.18 \mathrm{eV}$ for the smaller concentration $\left[\mathrm{M}^{2+}\right]=1.0 \times 10^{-6} \mathrm{~mol} / 1$.

It can be seen that the ionic substitutional energies tend to increase with decreasing $\mathrm{pH}$. This is because the $\mathrm{Ca}^{2+}$ concentration in the surrounding saturated solution $\left(\left[\mathrm{Ca}^{2+}\right]\right)$ becomes larger with decreasing solution $\mathrm{pH}$, as shown in Fig. 2. Owing to such $\mathrm{pH}$ dependence of $\left[\mathrm{Ca}^{2+}\right]$ on the solution, $\mathrm{Ca}^{2+}$ ions are more difficult to be released from HAp into the solution by the ion exchange in the lower $\mathrm{pH}$ condition so that the ionic substitutional energies become larger in more acidic conditions. ${ }^{17,24}$ Among the foreign cations, $\mathrm{Pb}^{2+}, \mathrm{Cd}^{2+}$, and $\mathrm{Sr}^{2+}$ exhibit the much smaller substitutional energies and, in particular, the substitutional energies of $\mathrm{Pb}^{2+}$ and $\mathrm{Cd}^{2+}$ are negative in the almost entire $\mathrm{pH}$ range.

As a matter of course, the ionic substitutional energies at the $\mathrm{Ca}-2$ site exhibit the same $\mathrm{pH}$ dependence with those at $\mathrm{Ca}-1$, but the absolute energy values are slightly different depending on the substitutional sites. In order to also show the Ca-site dependence of the substitutional energies, the calculated values at $\mathrm{pH}=7$ (neutral condition) at the two independent $\mathrm{Ca}$ sites are plotted against the ionic radii of the foreign cations in Fig. 5, where the ionic radii in the sixfold coordination are used. ${ }^{8}$

It is found that the variations in the substitutional energies against the ionic radii for the $\mathrm{Ca}-1$ and $\mathrm{Ca}-2$ substitutions are quite similar to each other. It is obvious that the smaller- or larger-sized cations than $\mathrm{Ca}^{2+}$ exhibit larger substitutional energies while substitution of $\mathrm{Cd}^{2+}, \mathrm{Sr}^{2+}$, and $\mathrm{Pb}^{2+}$ ions relatively similar in size to $\mathrm{Ca}^{2+}$ is energetically more favored. This can easily be imagined from simple consideration of ionic size mismatches between the foreign ions and $\mathrm{Ca}^{2+}$. As 


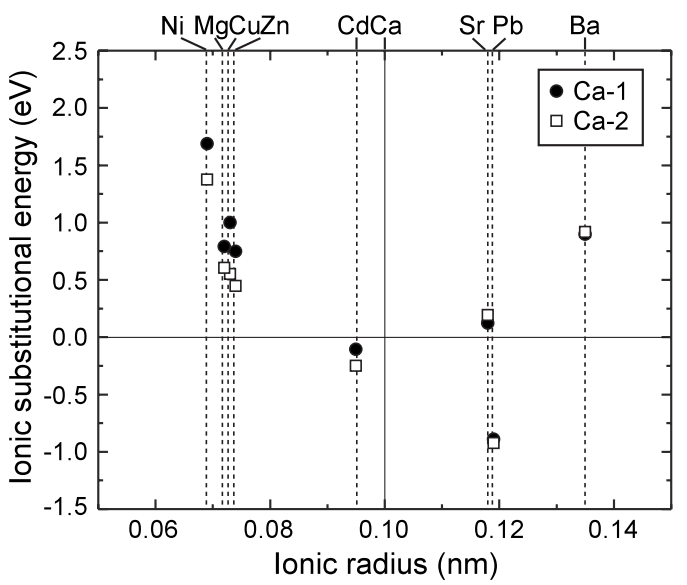

FIG. 5. Ionic substitutional energies at the $\mathrm{Ca}-1$ and $\mathrm{Ca}-2$ sites of HAp against the ionic radii. The energy values correspond to the ones at $\mathrm{pH}=7$ (see also Fig. 4).

displayed in Fig. 3, the smaller- and larger-sized foreign cations induce larger lattice relaxation of their surrounding ions by substitution and then suffer more significant elastic energy expenses.

It should be mentioned here, however, that the $\mathrm{Pb}^{2+}$ substitution exhibits the exceptionally small substitutional energy, even compared to the $\mathrm{Sr}^{2+}$ substitution with the quite similar ionic size. In such a case, the simple consideration of the ionic sizes is not available, and thus further detailed analyses of the electronic structures would be required. For this purpose, the partial densities of states (PDOS) of $\mathrm{Pb}^{2+}$ at $\mathrm{Ca}-1$ and its surrounding first NN oxygen ions are displayed in Fig. 6. For comparison, the PDOS curves for $\mathrm{Ca}^{2+}, \mathrm{Sr}^{2+}$, and $\mathrm{Cd}^{2+}$ at the Ca-1 site are also shown. As stated in our previous studies, the upper valence band $(\mathrm{VB})$ of perfect HAp is composed mainly of O $2 p$ orbitals, and the lower VB comprises $\mathrm{O} 2 s$ and $\mathrm{Ca} 3 p$ orbitals. For chemical bonding states in HAp, orbital overlap in the upper VB would be important, and the originally unoccupied $\mathrm{Ca} 3 d 4 \mathrm{~s}$ orbitals only slightly contribute to the upper VB [see Fig. 6(a)], which indicates a typical ionic nature of bonding between Ca-O. This is also the case for $\mathrm{Sr}^{2+}$ and $\mathrm{Cd}^{2+}$ in Figs. 6(b) and 6(c). It is noted that, in the case of $\mathrm{Cd}^{2+}$, the $\mathrm{Cd} 4 d$ orbitals considerably overlap with the $\mathrm{O} 2 p$ orbitals in the lower part of the upper $\mathrm{VB}$, but the $\mathrm{Cd}-4 d$ orbitals are originally fully occupied by electrons because the formal electronic configuration of $\mathrm{Cd}^{2+}$ is described as $[\mathrm{Kr}] 4 d^{10} 5 s^{0}$. Therefore, the orbital overlap between $\mathrm{Cd} 4 d$ and $\mathrm{O} 2 p$ does not directly contribute covalent interactions between $\mathrm{Cd}$ and O.

In the case of $\mathrm{Pb}^{2+}$, the original electronic configuration can be described as $[\mathrm{Hg}] 6 s^{2} 6 p^{0}$, and the electron-occupied $6 s$ orbitals appear in the lower part of the upper VB. It is worth mentioning here that the unoccupied $6 p$ orbitals are more admixed with $\mathrm{O} 2 p$ in the upper part of the upper VB, as compared to the $\mathrm{Ca}^{2+}, \mathrm{Sr}^{2+}$, and $\mathrm{Cd}^{2+}$ cases. It can be expected, therefore, that covalent interactions with the surrounding oxygen ions may be present in the $\mathrm{Pb}^{2+}$ substitution.

The role of $\mathrm{Pb} 6 s p$ orbitals for covalent bond formation has been qualitatively discussed. ${ }^{29,30}$ In an isolated state of
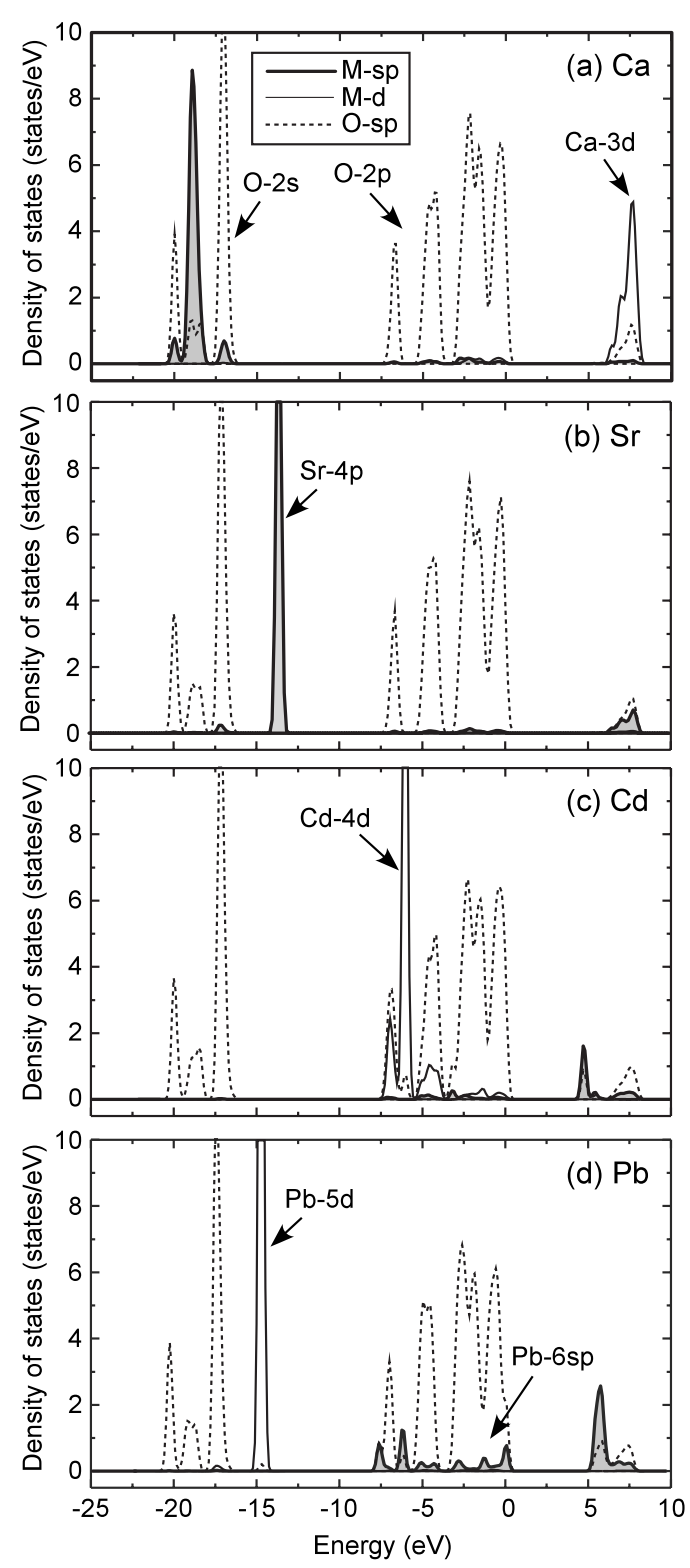

FIG. 6. PDOS curves of the cations and their first NN oxygen ions in HAp. In these plots, the valence-band maxima are set at $0 \mathrm{eV}$.

$\mathrm{Pb}^{2+}$, two $6 s$ electrons can simply be described as an inactive lone pair. However, depending on the atomic coordination environment, the unoccupied $\mathrm{Pb} 6 p$ orbitals are admixed with the $6 s$ orbitals. This results in formation of a "stereochemically active" lone pair. ${ }^{29,30}$ The active lone pair can strongly interact with $\mathrm{O} 2 p$ valence electrons in a bonding manner so that significant covalent bond formation around $\mathrm{Pb}^{2+}$ can be realized. This situation actually corresponds to the partial DOS curves in Fig. 6(d), where the Pb 6sp components are well admixed with the $\mathrm{O} 2 p$ components in the upper VB.

Figure 7 depicts contour maps of electron densities around $\mathrm{Pb}^{2+}$ and $\mathrm{Sr}^{2+}$ at the Ca-1 site on different cross sectional planes $[(1 \overline{1} 00)$ for (a) and (c) and (0001) for (b) and (d)]. It is noted that, in Fig. 7(a), $\mathrm{Ca}^{2+}$ and $\mathrm{Pb}^{2+}$ ions at the Ca-1 sites and their first NN oxygen ions are located close to 


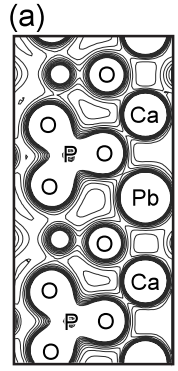

(c)
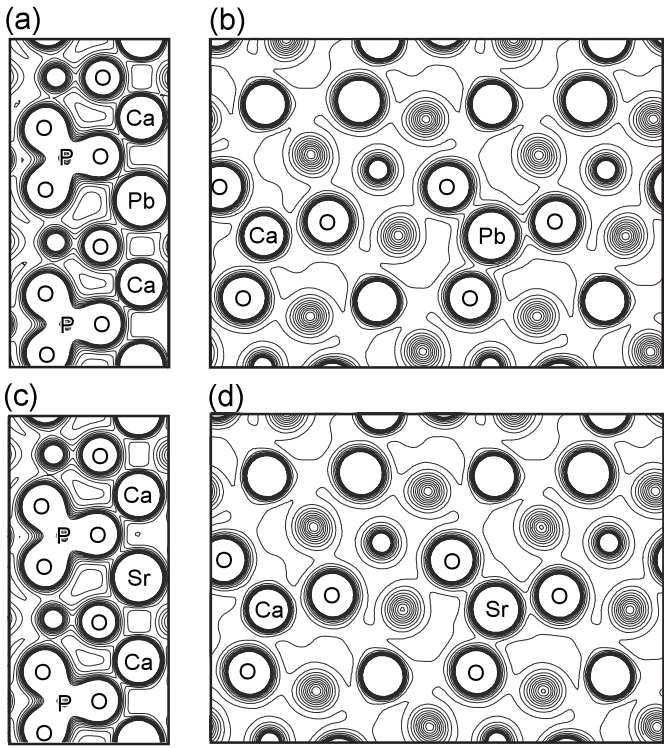

(d)

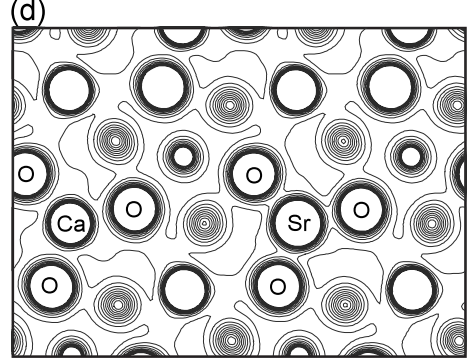

FIG. 7. Contour maps of electron densities on the [(a) and (c)] $(1 \overline{1} 00)$ and [(a) and (c)] (0001) planes for HAp with $\mathrm{Pb}^{2+}$ and $\mathrm{Sr}^{2+}$ at the $\mathrm{Ca}-1$ sites. The contour lines are drawn from 0.00 to 0.50 with an interval of $0.05 \mathrm{e} / \AA$ (Ref. 3).

the cross sectional plane while the cations and their second NN oxygen ions are present close to the cross section in Fig. 7(b). This is also the case for $\mathrm{Sr}^{2+}$ in Figs. 7(c) and 7(d).

It can be seen in Fig. 7(a) that more electrons tend to be accumulated between $\mathrm{Pb}-\mathrm{O}$, as compared to those in the interatomic region of $\mathrm{Ca}-\mathrm{O}$ [see Fig. 7(a)]. Moreover, the Ca-1 ions do not exhibit apparent electron densities in the interatomic region with the second $\mathrm{NN}$ oxygen ions, but it is obvious that the doped $\mathrm{Pb}^{2+}$ ion also shows more electrondensity overlap with the second NN oxygen [see Fig. 7(b)]. These results are an indication of the strong tendency of covalent bond formation of $\mathrm{Pb}^{2+}$ with the surrounding oxygen atoms. In this regard, Ellis et al. ${ }^{30}$ also investigated $\mathrm{Pb}$ substitution in HAp by the similar first-principles method and analyzed the local atomic coordination and chemical bonding state. They showed that $\mathrm{Pb}$ substitution in HAp cannot simply be described by substitution of a rigid $\mathrm{Pb}^{2+}$ ion but accompanies strong covalent interactions with the surrounding oxygen atoms, which is consistent with the present result. It is noted that relativistic effects on $\mathrm{Pb}$ valence orbitals were also examined by the above authors but were found not to significantly alter the covalent bonding character between $\mathrm{Pb}$ and $\mathrm{O} .{ }^{30}$

In the case of the $\mathrm{Sr}^{2+}$ substitution at the $\mathrm{Ca}-1$ site [Fig. 7(c) and 7(d)], the ionic size of $\mathrm{Sr}^{2+}$ is quite similar to that of $\mathrm{Pb}^{2+}$ (see Fig. 3), but the substitutional energy is considerably larger than that of $\mathrm{Pb}^{2+}$ (see Fig. 5). In this case, the larger electron-density overlap between $\mathrm{Sr}$ and its surrounding oxygen can also be observed (especially with the second $\mathrm{NN}$ oxygen), as compared to that of $\mathrm{Ca}-\mathrm{O}$. However, the electron densities of $\mathrm{Sr}-\mathrm{O}$ are still smaller than those of $\mathrm{Pb}-\mathrm{O}$. Therefore, the extremely stable substitution of $\mathrm{Pb}^{2+}$ can be attributed to the formation of strong covalent bonds with the adjacent oxygen atoms.

Based on the above results, the ion exchange ability by HAp is predicted to be in the order of $\mathrm{Pb}^{2+}>\mathrm{Cd}^{2+}>\mathrm{Sr}^{2+}$
$>\mathrm{Zn}^{2+}>\mathrm{Cu}^{2+}>\mathrm{Mg}^{2+}>\mathrm{Ba}^{2+}>\mathrm{Ni}^{2+}$. The previous ion exchange experiments by Suzuki et al. ${ }^{1,2}$ also showed that $\mathrm{Pb}^{2+}$ and $\mathrm{Cd}^{2+}$ ions are more favorably uptaken by HAp from the solution. Yasukawa et al. ${ }^{31}$ discussed the ranking of preferential incorporation of divalent foreign cations into HAp based on their experimental data and indicated the order of $\mathrm{Ca}^{2+}>\mathrm{Mg}^{2+}$ and $\mathrm{Pb}^{2+}>\mathrm{Ca}^{2+}>\mathrm{Sr}^{2+}>\mathrm{Ba}^{2+}$. They also mentioned that $\mathrm{Pb}^{2+}$ and $\mathrm{Cd}^{2+}$ are, in particular, easy to be incorporated by exchange with $\mathrm{Ca}^{2+}$ in HAp. There were also a number of experimental studies synthesizing $\mathrm{Pb}_{10}\left(\mathrm{PO}_{4}\right)_{6}(\mathrm{OH})_{2}, \mathrm{Sr}_{10}\left(\mathrm{PO}_{4}\right)_{6}(\mathrm{OH})_{2}$, and $\mathrm{Cd}_{10}\left(\mathrm{PO}_{4}\right)_{6}(\mathrm{OH})_{2}$ by solution-precipitation methods. ${ }^{9,31-35}$ In this regard, the present results show that the substitutional energies of $\mathrm{Pb}^{2+}$, $\mathrm{Cd}^{2+}$, and $\mathrm{Sr}^{2+}$ are much smaller than those of the other ions (Figs. 4 and 5), whose tendency is consistent with the previous experimental results.

It is noted that the calculated ranking of the ion exchange ability except for $\mathrm{Pb}^{2+}, \mathrm{Cd}^{2+}$, and $\mathrm{Sr}^{2+}$ seems different from the experimental result of $\mathrm{Cd}^{2+}, \mathrm{Zn}^{2+}>\mathrm{Ni}^{2+}>\mathrm{Ba}^{2+}, \mathrm{Mg}^{2+}$ by Suzuki et al. ${ }^{1,2}$ It is plausible that the discrepancy may be related to the presence of a transition layer between HAp and the surrounding solution. As discussed by Tung et al., ${ }^{36}$ it is thought that surface structures of HAp in contact with an aqueous solution are different from the case in contact with vacuum and a disordered and/or hydrated transition layer may be present at the interface. Such a transition layer is expected to strongly affect uptake and exchange processes for foreign ions by HAp so that the transition layer may affect the apparent solubility of the cations. This would be especially true for the ions having the relatively large substitutional energies into HAp. There is a possibility that the cations cannot be incorporated into the HAp lattice but can be favorably included in the transition layer. In fact, $\mathrm{Mg}^{2+}$ and $\mathrm{Zn}^{2+}$ incorporations in the transition layer were investigated in our previous study, where octacalcuim phosphate (OCP) was used as a prototype for the transition layer. ${ }^{17}$ It was found that the substitutional energies in the transition layer were much smaller than in HAp, depending on the substitutional sites. Therefore, further studies will be required to make more quantitative discussion on the ranking of the cations having the high substitutional energies.

Regarding the site preference of the substituted cations in HAp, the present results in Fig. 5 indicate that the smallersized cations prefer the $\mathrm{Ca}-2$ substitution while the larger cations favor the Ca-1 substitution except for $\mathrm{Pb}^{2+}$. Table I shows the available experimental data of the preferential occupation sites of divalent foreign cations. ${ }^{9,37-40}{\text { For } \mathrm{Cd}^{2+} \text { and }}^{2}$ $\mathrm{Pb}^{2+}$, an agreement between the present calculations and the experiment can be achieved, but there are the discrepancies for $\mathrm{Sr}^{2+}$ between theory and experiment. Kikuchi et al. ${ }^{38}$ showed that $\mathrm{Sr}^{2+}$ prefers the Ca-1 site substitution in HAp, which is consistent with the present result. However, Hughes et al. $^{39}$ experimentally analyzed naturally occurring $\mathrm{Sr}$ substituted apatite samples with more than about $3 \mathrm{~mol} \%$ of $\mathrm{Sr}$ and showed that the $\mathrm{Sr}$ substitution is favored to the $\mathrm{Ca}-2$ site. In this case, it is noted that the samples also contained other trace elements of sodium, silicon, and so on, which may affect the $\mathrm{Sr}$ substitutional behavior. More recent $\mathrm{Ri}$ etveld analyses of solid solutions of Sr-Ca HAp by Zhu et $a l .{ }^{9}$ also indicated that $\mathrm{Sr}^{2+}$ favors occupation of the $\mathrm{Ca}-2$ site 
TABLE I. Comparison of preferential substitutional site for divalent cations between experiment and the present study.

\begin{tabular}{lcc}
\hline \hline Cation species & Experiment & The present work \\
\hline $\mathrm{Cd}^{2+}$ & $\mathrm{Ca}-2^{\mathrm{a}}, \mathrm{b}$ & $\mathrm{Ca}-2$ \\
$\mathrm{Sr}^{2+}$ & $\mathrm{Ca}-1,{ }^{\mathrm{c}} \mathrm{Ca}-2^{\mathrm{a},}$, & $\mathrm{Ca}-1$ \\
$\mathrm{~Pb}^{2+}$ & $\mathrm{Ca}-2^{\mathrm{a}}$, & $\mathrm{Ca}-2$ \\
\hline
\end{tabular}

aReference 9 .

${ }^{\mathrm{b}}$ Reference 37.

${ }^{\mathrm{c}}$ Reference 38 .

${ }^{\mathrm{d}}$ Reference 39.

${ }^{\mathrm{e}}$ Reference 40.

in the range of higher $\mathrm{Sr}$ content, whereas $\mathrm{Sr}^{2+}$ does not show significant site preference in the lower $\mathrm{Sr}$ content. Strictly speaking, the present calculations correspond to the dilute substitution of $\mathrm{Sr}^{2+}$ in HAp, and thus it is not reasonable to make direct comparison of the present result of the site preference with the above-mentioned experiment with much higher $\mathrm{Sr}^{2+}$ content. As shown in Fig. 5, however, the difference in substitutional energies between the two Ca sites for $\mathrm{Sr}^{2+}$ is somewhat small (about $0.07 \mathrm{eV}$ ) and therefore $\mathrm{Sr}^{2+}$ may not exhibit pronounced site preference in the low $\mathrm{Sr}^{2+}$ content range, as shown in Ref. 9.

It is finally noted that the Sr content in HAp can be roughly calculated to be around $1 \mathrm{~mol} \%$ in the range of $\mathrm{pH}=7-8$ based on the result of Fig. $4 .{ }^{17}$ Although the calculated $\mathrm{Sr}$ content in HAp is much smaller than those by the previous experiments, ${ }^{9}$ it is worth mentioning that the equilibrium concentration may strongly depend on experimental conditions to produce the HAp materials. Even in the present case, as shown in Fig. 4, the Sr-substituted energy tends to decrease with increasing $\mathrm{pH}$ and $\left[\mathrm{Sr}^{2+}\right]$ in solution. Therefore, more intense Sr substitution may be possible, depending on experimental conditions of the ion exchange process (more alkaline and higher $\left[\mathrm{Sr}^{2+}\right]$ conditions). In the system with more $\mathrm{Sr}$ substitutions, however, $\mathrm{Sr}-\mathrm{Sr}$ interactions and the distribution and configuration of substitutional $\mathrm{Sr}$ ions would become important to calculate the equilibrium Sr concentration, which needs to be correctly taken into account in future, from a theoretical viewpoint.

\section{CONCLUSIONS}

First-principles calculations were performed for HAp, to study ion exchange ability of the divalent cations. Chemical equilibrium between HAp and its saturated solution was assumed, and the chemical potentials for the foreign cations then obtained were used to evaluate the ionic substitutional energies. It was found that the ion exchange ability is basically dependent on the ionic sizes. The larger or smallersized cations than $\mathrm{Ca}^{2+}$ tend to exhibit more difficulty of substitution for Ca in HAp. However, it is worth mentioning that $\mathrm{Pb}^{2+}$ exhibits the extremely small substitutional energy, which originates from covalent bond formation with the adjacent oxygen ions. Therefore, the detailed chemical bonding state plays an important role for the good ion exchange ability for $\mathrm{Pb}^{2+}$ by $\mathrm{HAp}$.

\section{ACKNOWLEDGMENTS}

This study was supported by Grant-in-Aid for Scientific Research on Priority Areas "Nano Materials Science for Atomic Scale Modification 474" from Ministry of Education, Culture, Sports, Science and Technology of Japan (MEXT). The authors would like to acknowledge I. Tanaka for his support of computation.
${ }^{1}$ T. Suzuki, T. Hatsushika, and Y. Hayakawa, J. Chem. Soc., Faraday Trans. 77, 1059 (1981).

${ }^{2}$ T. Suzuki, T. Hatsushika, and M. Miyake, J. Chem. Soc., Faraday Trans. 77, 3605 (1982).

${ }^{3}$ J. C. Elliot, Structure and Chemistry of the Apatites and other Calcium Orthophosphates (Elsevier, Amsterdam, 1994).

${ }^{4}$ Y. Takeuchi and H. Arai, J. Chem. Eng. Jpn. 23, 75 (1990).

${ }^{5}$ S. Suzuki, T. Fuzita, T. Maruyama, and M. Takahashi, J. Am. Ceram. Soc. 76, 1638 (1993).

${ }^{6}$ A. Yasukawa, T. Yokoyama, K. Kandori, and T. Ishikawa, Colloids Surf., A 238, 133 (2004).

${ }^{7}$ S. Lazić, and Ž. Vuković, J. Radioanal. Nucl. Chem. 149, 161 (1991).

${ }^{8}$ R. A. Shannon, Acta Crystallogr., Sect. A: Cryst. Phys., Diffr., Theor. Gen. Crystallogr. 32, 751 (1976).

${ }^{9}$ K. Zhu, K. Yanagisawa, R. Shimanouchi, A. Onda, and K. Kajiyoshi, J. Eur. Ceram. Soc. 26, 509 (2006).

${ }^{10}$ S. Cazalbou, D. Eichert, X. Ranz, C. Drouet, C. Combes, M. F. Harmand, and C. Rey, J. Mater. Sci. 16, 405 (2005).

${ }^{11}$ D. U. Schramm, J. Terra, A. M. Rossi, and D. E. Ellis, Phys. Rev. B 63, 024107 (2000).

${ }^{12}$ M. Jiang, J. Terra, A. M. Rossi, M. A. Morales, E. M. Baggio
Saitovitch, and D. E. Ellis, Phys. Rev. B 66, 224107 (2002).

${ }^{13}$ J. Terra, M. Jiang, and D. E. Ellis, Philos. Mag. 82, 2357 (2002).

${ }^{14}$ R. Astala and M. J. Stott, Chem. Mater. 17, 4125 (2005).

${ }^{15}$ R. Astala, L. Calderín, X. Yin, and M. J. Stott, Chem. Mater. 18, 413 (2006).

${ }^{16}$ X. Ma and D. E. Ellis, Biomaterials 29, 257 (2008).

${ }^{17}$ K. Matsunaga, J. Chem. Phys. 128, 245101 (2008).

${ }^{18}$ G. Kresse and J. Furthmüller, Phys. Rev. B 54, 11169 (1996).

${ }^{19}$ P. E. Blöchl, Phys. Rev. B 50, 17953 (1994).

${ }^{20}$ G. Kresse and D. Joubert, Phys. Rev. B 59, 1758 (1999).

${ }^{21}$ J. P. Perdew, K. Burke, and M. Ernzerhof, Phys. Rev. Lett. 77, 3865 (1996).

${ }^{22}$ H. J. Monkhorst and J. D. Pack, Phys. Rev. B 13, 5188 (1976).

${ }^{23}$ M. I. Kay, R. A. Young, and A. S. Posner, Nature (London) 204, 1050 (1964).

${ }^{24}$ K. Matsunaga, Phys. Rev. B 77, 104106 (2008).

${ }^{25}$ J. R. Pliego, Jr., and J. M. Riveros, Chem. Phys. Lett. 332, 597 (2000).

${ }^{26}$ J. Llano and L. A. Eriksson, J. Chem. Phys. 117, 10193 (2002).

${ }^{27}$ D. D. Wagman, W. H. Evans, V. B. Parker, R. H. Schumm, I. Halow, S. M. Bailey, K. L. Churney, and R. L. Nuttall, J. Phys. Chem. Ref. Data 11, 1 (1982). 
${ }^{28}$ S. Chander and D. W. Fuerstenau, J. Colloid Interface Sci. 70, 506 (1979).

${ }^{29}$ J. A. Thompson, B. L. Scott, and N. N. Sauer, Acta Crystallogr., Sect. A: Found. Crystallogr. 54, 734 (1998).

${ }^{30}$ D. E. Ellis, J. Terra, O. Warschkow, M. Jiang, G. B. González, J. S. Okasinski, M. J. Bedzyk, A. M. Rossi, and J. G. Eon, Phys. Chem. Chem. Phys. 8, 967 (2006).

${ }^{31}$ A. Yasukawa, M. Higashijima, K. Kandori, and T. Ishikawa, Colloids Surf., A 268, 111 (2005).

${ }^{32}$ A. Yasukawa, T. Kunimoto, K. Kamiuchi, K. Kandori, and T. Ishikawa, J. Mater. Chem. 9, 1825 (1999).

${ }^{33}$ R. L. Collin, J. Am. Chem. Soc. 82, 5067 (1960).

${ }^{34}$ T. Ishikawa, H. Saito, A. Yasukawa, and K. Kandori, J. Chem. Soc., Faraday Trans. 89, 3821 (1993).
${ }^{35}$ A. Yasukawa, T. Yokoyama, and T. Ishikawa, Mater. Res. Bull. 36, 775 (2001).

${ }^{36}$ M. S. Tung and D. Skrtic, in Octacalcium Phosphate, Monograph in Oral Science, Vol. 18, edited by L. C. Chow, and E. D. Eanes, (Karger, Basel, 2001), p. 112.

${ }^{37}$ J. Jeanjean, U. Vincent, and M. Fedoroff, J. Solid State Chem. 108, 68 (1994).

${ }^{38}$ M. Kikuchi, A. Yamazaki, R. Otsuka, M. Akao, and H. Aoki, J. Solid State Chem. 113, 373 (1994).

${ }^{39}$ J. M. Hughes, M. Cameron, and K. D. Crowley, Am. Mineral. 76, 1857 (1991).

${ }^{40}$ R. M. H. Verbeeck, C. J. Lassuyt, H. J. M. Heijligers, F. C. M. Driessens, and J. W. G. A. Vrolijk, Calcif. Tissue Int. 33, 243 (1981). 